\title{
Spike Activity Regulates Vesicle Filling at a Glutamatergic Synapse
}

\author{
Dainan Li, ${ }^{1}$ Yun Zhu, ${ }^{1}$ and ${ }^{\circledR}$ Hai Huang ${ }^{1,2}$ \\ ${ }^{1}$ Department of Cell and Molecular Biology, and ${ }^{2}$ Brain Institute, Tulane University, New Orleans, Louisiana 70118
}

Synaptic vesicles need to be recycled and refilled rapidly to maintain high-frequency synaptic transmission. However, little is known about the control of neurotransmitter transport into synaptic vesicles, which determines the contents of synaptic vesicles and the strength of synaptic transmission. Here, we report that $\mathrm{Na}^{+}$substantially accumulated in the calyx of Held terminals of juvenile mice of either sex during high-frequency spiking. The activity-induced elevation of cytosolic $\mathrm{Na}^{+}$activated vesicular $\mathrm{Na}^{+} / \mathrm{H}^{+}$exchanger, facilitated glutamate loading into synaptic vesicles, and increased quantal size of asynchronous released vesicles but did not affect the vesicle pool size or release probability. Consequently, presynaptic $\mathrm{Na}^{+}$ increased the EPSCs and was required to maintain the reliable high-frequency signal transmission from the presynaptic calyces to the postsynaptic medial nucleus of the trapezoid body (MNTB) neurons. Blocking $\mathrm{Na}^{+} / \mathrm{H}^{+}$exchange activity decreased the postsynaptic current and caused failures in postsynaptic firing. Therefore, during high-frequency synaptic transmission, when large amounts of glutamate are released, $\mathrm{Na}^{+}$accumulated in the terminals, activated vesicular $\mathrm{Na}^{+} / \mathrm{H}^{+}$exchanger, and regulated glutamate loading as a function of the level of vesicle release.

Key words: axon terminal; calyx of Held; glutamate; spiking; synaptic vesicle; vesicular glutamate transport

\section{Significance Statement}

Auditory information is encoded by action potentials (APs) phase-locked to sound frequency at high rates. A large number of synaptic vesicles are released during high-frequency synaptic transmission; accordingly, synaptic vesicles need to be recycled and refilled rapidly. We have recently found that a $\mathrm{Na}^{+} / \mathrm{H}^{+}$exchanger expressed on synaptic vesicles promotes vesicle filling with glutamate. Here, we showed that when a large number of synaptic vesicles are released during high-frequency synaptic transmission, $\mathrm{Na}^{+}$accumulates in axon terminals and facilitates glutamate uptake into synaptic vesicles. $\mathrm{Na}^{+}$thus accelerates vesicle replenishment and sustains reliable synaptic transmission.

\section{Introduction}

High-frequency firing neurons are widely distributed throughout the central nervous system, including the brainstem, cerebellum, thalamus, hippocampus, and neocortex (McCormick et al., 1985; Chen and Regehr, 1999; Rudy and McBain, 2001; Taschenberger et al., 2002; Hu and Jonas, 2014). Accordingly, synaptic vesicles need to be recycled and refilled rapidly to support the high-frequency synaptic signaling (Rizzoli and Betz, 2005; Edwards, 2007; Farsi et al., 2017). Accumulating studies have uncovered the mechanisms of vesicle fusion and recycling (Heuser and Reese, 1973; Klingauf et al., 1998; Wang and Kaczmarek, 1998;

\footnotetext{
Received Dec. 10, 2019; revised May 10, 2020; accepted May 12, 2020

Author contributions: D.L., Y.Z., and H.H. designed research; D.L., Y.Z., and H.H. performed research; D.L., Y.Z., and H.H. analyzed data; D.L., Y.Z., and H.H. wrote the paper.

The authors declare no competing financial interests.

This work was supported by the National Institutes of Health Grant R01DC016324 (to H.H.). We thank Dr. Larry Trussell, Dr. Jeffery Tasker, Dr. Laura Schrader, Ms. Youad Darwish, and Mr. Chen Wei Goh for critical reading and comments on the manuscript.

Correspondence should be addressed to Hai Huang at hhuang5@tulane.edu.

https://doi.org/10.1523/JNEUROSCI.2945-19.2020

Copyright $\odot 2020$ the authors
}

Sudhof, 2004); however, the control of the contents of synaptic vesicles has received considerably less attention (Balmer and Trussell, 2016). Recent studies showed that synaptic vesicles express $\mathrm{Na}^{+} / \mathrm{H}^{+}$monovalent cation exchanger (NHE) activity that converts the $\mathrm{pH}$ gradient into an electrical potential required by the vesicular glutamate transporter (VGluT; Goh et al., 2011; Preobraschenski et al., 2014). $\mathrm{Na}^{+}$flux through $\mathrm{HCN}$ channels enhances presynaptic $\mathrm{Na}^{+}$concentration and thus promotes synaptic vesicle filling with glutamate (Huang and Trussell, 2014). However, how spike activity controls the presynaptic $\mathrm{Na}^{+}$ dynamics and how accumulated $\mathrm{Na}^{+}$modulates synaptic transmission are unknown. Using the mouse calyx of Held, a giant glutamatergic synapse in the medial nucleus of the trapezoid body (MNTB) of the auditory brainstem that permits direct presynaptic and postsynaptic recordings and manipulation of the presynaptic cytosolic environment, we showed that glutamate loading is facilitated by intracellular $\mathrm{Na}^{+}$over the physiological concentration range. During high-frequency signaling, when large amounts of glutamate are released, $\mathrm{Na}^{+}$accumulates in terminals, activates NHE, and facilitates glutamate uptake into synaptic vesicles, thus accelerating vesicle refilling and sustaining 
reliable synaptic transmission. Therefore, presynaptic cytosolic $\mathrm{Na}^{+}$works as a signaling ion to coordinate glutamate loading as a function of the level of vesicle release.

\section{Materials and Methods}

\section{Slice preparation}

All animal handling and procedures were approved by the Institutional Animal Care and Use Committee of Tulane University and followed United States Public Health Service guidelines. Coronal brainstem slices containing the MNTB were prepared from C57BL/6J mice of either sex aged postnatal day (P)8-P16, being similar to previously described (Zhang and Huang, 2017). Briefly, mice brainstems were dissected, and $210-\mu \mathrm{m}$ sections were sliced using a vibratome (VT1200S, Leica) in icecold, low- $\mathrm{Ca}^{2+}$, low- $\mathrm{Na}^{+}$saline contained the following: $230 \mathrm{~mm}$ sucrose, 10-25 mм glucose, $2.5 \mathrm{~mm} \mathrm{KCl,} 3 \mathrm{~mm} \mathrm{MgCl}$, $0.1 \mathrm{~mm} \mathrm{CaCl}_{2}, 1.25$ $\mathrm{mm} \mathrm{NaH} \mathrm{PO}_{4}, 25 \mathrm{~mm} \mathrm{NaHCO}, 0.4 \mathrm{~mm}$ ascorbic acid, $3 \mathrm{~mm}$ myo-inositol, and $2 \mathrm{~mm}$ Na-pyruvate, bubbled with $95 \% \mathrm{O}_{2} / 5 \% \mathrm{CO}_{2}$. Slices were immediately incubated at $32^{\circ} \mathrm{C}$ for $20-40 \mathrm{~min}$ and subsequently stored at room temperature in normal artificial CSF (aCSF) contained the following: $125 \mathrm{~mm} \mathrm{NaCl}, 10-25 \mathrm{~mm}$ glucose, $2.5 \mathrm{~mm} \mathrm{KCl}, 1.8 \mathrm{~mm} \mathrm{MgCl}_{2}, 1.2$ $\mathrm{mm} \mathrm{CaCl}_{2}, 1.25 \mathrm{~mm} \mathrm{NaH}_{2} \mathrm{PO}_{4}, 25 \mathrm{~mm} \mathrm{NaHCO}_{3}, 0.4 \mathrm{~mm}$ ascorbic acid, 3 mM myo-inositol, and $2 \mathrm{~mm}$ Na-pyruvate, $\mathrm{pH} 7.4$ bubbled with $95 \%$ $\mathrm{O}_{2} / 5 \% \mathrm{CO}_{2}$.

\section{Whole-cell recordings}

Slices were transferred to a recording chamber and perfused with normal aCSF $\left(2-3 \mathrm{ml} / \mathrm{min}\right.$ ) warmed to $\sim 32^{\circ} \mathrm{C}$ by an in-line heater (Warner Instruments). Neurons were visualized using an Olympus BX51 microscope with a $60 \times$ water-immersion objective and custom infrared Dodt gradient contrast optics. Whole-cell patch-clamp recordings were performed with a Multiclamp 700B amplifier (Molecular Devices) except for the capacitance measurements. Pipettes pulled from thick-walled borosilicate glass capillaries (WPI) had open tip resistances of 3-5 and 2-3 $\mathrm{M} \Omega$ for the presynaptic and postsynaptic recordings, respectively. Series resistance (4-15 M $\Omega$ ) was compensated by up to $70 \%$ (bandwidth $3 \mathrm{kHz}$ ). To record presynaptic action potentials (APs) under different $\mathrm{Na}^{+}$concentration, pipette solution contained the following: $60 \mathrm{mM} \mathrm{K}-$ methanesulfonate, $20 \mathrm{~mm} \mathrm{KCl}, 10 \mathrm{~mm}$ HEPES, $0.5 \mathrm{~mm}$ EGTA, $4 \mathrm{~mm}$ Mg-ATP, $0.3 \mathrm{~mm}$ Tris $_{3}$-GTP, $14 \mathrm{~mm}$ Tris $_{2}$-phosphocreatine, and $5 \mathrm{~mm}$ glutamate, as well as $40 \mathrm{~mm}$ NMDG-methanesulfonate (for $\mathrm{Na}^{+}$-free solution), $10 \mathrm{~mm}$ Na-methanesulfonate $+30 \mathrm{~mm}$ NMDG-methanesulfonate (for $10 \mathrm{~mm} \mathrm{Na}^{+}$solution), or $40 \mathrm{~mm} \mathrm{Na}$-methanesulfonate (for 40 $\mathrm{mm} \mathrm{Na}{ }^{+}$solution). Solutions were adjusted to $\mathrm{pH} 7.3$ with $\mathrm{KOH}(290$ $\mathrm{mOsm}$ ), and the final $\mathrm{K}^{+}$for all solutions was around $92 \mathrm{~mm}$. For presynaptic voltage-clamp recordings, pipette solution contained the following: $70 \mathrm{~mm}$ Cs-methanesulfonate, $20 \mathrm{~mm} \mathrm{CsCl}, 10 \mathrm{~mm}$ HEPES, $0.5 \mathrm{~mm}$ EGTA, 4 mM Mg-ATP, $0.3 \mathrm{~mm}$ Tris $_{3}$-GTP, $10 \mathrm{~mm}$ Tris 2 -phosphocreatine, and $5 \mathrm{~mm}$ glutamate, as well as $40 \mathrm{~mm}$ NMDG-methanesulfonate (for $\mathrm{Na}^{+}$-free solution), $10 \mathrm{~mm}$ Na-methanesulfonate $+30 \mathrm{~mm}$ NMDGmethanesulfonate (for $10 \mathrm{mM} \mathrm{Na}^{+}$solution), or $40 \mathrm{~mm} \mathrm{Na}$-methanesulfonate (for $40 \mathrm{~mm} \mathrm{Na}^{+}$solution). Solutions were adjusted to $\mathrm{pH} 7.3$ with $\mathrm{CsOH}(310-315 \mathrm{mOsm})$. To isolate presynaptic $\mathrm{Ca}^{2+}$ currents in response to voltage steps, TEA-Cl (10 mM), and 4-AP (2 mM) and tetrodotoxin $(1 \mu \mathrm{M})$ were added to aCSF, substituting for $\mathrm{NaCl}$ with equal osmolarity. For EPSC recordings, postsynaptic pipette solution contained the following: $130 \mathrm{~mm}$ Cs-methanesulfonate, $10 \mathrm{~mm} \mathrm{CsCl,} 10 \mathrm{~mm}$ HEPES, 5 mm EGTA, 4 mM Mg-ATP, $0.3 \mathrm{~mm}$ Tris $_{3}$-GTP, $5 \mathrm{~mm} \mathrm{Na}_{2}-$ phosphocreatine, and $2 \mathrm{~mm}$ QX-314-Cl $(290$ mOsm, pH 7.3 with $\mathrm{CsOH}$ ). Recording aCSF contained $5 \mu \mathrm{M}(\mathrm{R})-\mathrm{CPP}, 50 \mu \mathrm{M}$ picrotoxin, and $1 \mu \mathrm{M}$ strychnine to block NMDA, GABA, and glycine receptors, respectively; $2 \mathrm{~mm}$ kynurenic acid and $100 \mu \mathrm{M}$ cyclothiazide were applied to block AMPA receptor saturation and desensitization, respectively (Barnes-Davies and Forsythe, 1995; Huang and Trussell, 2011). For postsynaptic spiking recordings, pipette solution contained the following: $135 \mathrm{~mm}$ K-gluconate, $10 \mathrm{~mm} \mathrm{KCl,} 10 \mathrm{~mm}$ HEPES, $0.2 \mathrm{~mm}$ EGTA, $4 \mathrm{~mm}$ Mg-ATP, $0.3 \mathrm{~mm} \mathrm{Tris}{ }_{3}$-GTP, and $7 \mathrm{~mm} \mathrm{Na}$-phosphocreatine (290 mOsm, $\mathrm{pH} 7.3$ with $\mathrm{KOH}$ ). To record the asynchronous release, extracellular $\mathrm{Ca}^{2+}$ was replaced by $\mathrm{Sr}^{2+}(7.5 \mathrm{~mm})$. Presynaptic APs were evoked by afferent fiber stimulation with a bipolar stimulating electrode placed close to the midline of slices. Liquid junction potentials were measured for all solutions, and reported voltages are appropriately adjusted.

\section{Perforated patch-clamp recordings}

Perforated whole-cell patch-clamp recordings were used during prolonged high-frequency postsynaptic recordings. The pipette solution was similar to that for conventional whole-cell postsynaptic spiking recordings, while gramicidin (final concentration of $60 \mu \mathrm{g} / \mathrm{ml}$ ) was added immediately before use. The tip of the recording pipette was first filled with gramicidin-free solution and then back-fill with gramicidin-containing solution. The degree of perforation was monitored after formation of gigaohm seal and recordings were started after overall access resistance dropped to below $30 \mathrm{M} \Omega$.

\section{Two-photon $\mathrm{Na}^{+}$-imaging}

A Galvo multiphoton microscopy system (Scientifica) with a Ti:sapphire pulsed laser (Chameleon Ultra II; Coherent) was used for two-photon $\mathrm{Na}^{+}$ imaging (Bender et al., 2010). The laser was tuned to $800 \mathrm{~nm}$, epifluorescence signals were captured through $60 \times, 1.0 \mathrm{NA}$ objectives, and a $1.4 \mathrm{NA}$ oil immersion condenser (Olympus). Fluorescence was split into red and green channels using dichroic mirrors and bandpass filters. Data were collected in line-scan or frame-scan modes. The pipette solution contained the following: $110 \mathrm{~mm}$ K-methanesulfonate, $20 \mathrm{~mm} \mathrm{KCl}, 10 \mathrm{~mm}$ HEPES, 0.5 mM EGTA, 4 mм Mg-ATP, $0.3 \mathrm{~mm} \mathrm{Tris}_{3}$-GTP, and $5 \mathrm{~mm} \mathrm{Na}_{2}$-phosphocreatine ( 290 mOsm; pH 7.3 with $\mathrm{KOH}$ ), while $1 \mathrm{~mm}$ SBFI and $15 \mu \mathrm{M}$ Alexa Fluor 594 were added to the pipette solution before the experiments. Presynaptic spikes were evoked by afferent fiber stimulation or current injection, and corresponding $\mathrm{Na}^{+}$signals were recorded under two-photon imaging. Standard calibration methods were used to measure the absolute $\mathrm{Na}^{+}$concentrations (Rose, 2012; Huang and Trussell, 2014).

\section{Membrane capacitance $\left(\mathrm{C}_{\mathrm{m}}\right)$ measurements}

Whole-cell patch-clamp recordings were made with an EPC-10 USB double amplifier controlled by Patchmaster software (HEKA) to record presynaptic calcium current and $\mathrm{C}_{\mathrm{m}}$ response. The calyx of Held terminals were voltage-clamped at holding potential of $-80 \mathrm{mV}$ with a sinusoidal wave $(60-\mathrm{mV}$ peak-to-peak amplitude at $1 \mathrm{kHz})$ superimposed (Sun and $\mathrm{Wu}, 2001$ ). Tips of patch pipettes were coated with dental wax to reduce capacitance. Series resistance (6-20 M 2 ) was electronically compensated by up to $75 \%(10-\mu \mathrm{s}$ lag). The calyceal terminals were depolarized from -80 to $+10 \mathrm{mV}$ for 1 and $30 \mathrm{~ms}$ to mimic the APinduced release and to deplete the releasable pool, respectively. Recordings were performed at $32^{\circ} \mathrm{C}$. Data were obtained within $20 \mathrm{~min}$ after break-in and sampled at $100 \mathrm{kHz}$.

\section{Drugs}

Drugs were obtained from Tocris (H-89), Alomone (tetrodotoxin, CPP, cyclothiazide), Invitrogen (SBFI and Alexa Fluor 594), and all others from Sigma-Aldrich.

\section{Analysis}

Data were analyzed using Clampfit (Molecular Devices), Patchmaster (HEKA), Igor (WaveMetrics), and ImageJ (NIH). Data are expressed as mean \pm SEM. Statistical significance was established using paired and unpaired $t$ tests, and ANOVA as noted, with $p<0.05$ indicating a significant difference.

\section{Results}

\section{Spikes control presynaptic cytosolic $\mathrm{Na}^{+}$concentration}

$\mathrm{Na}^{+}$flows into the cytosol during the firing of APs, while the location of $\mathrm{Na}^{+}$channels in the calyx of Held is under debate (Leão et al., 2005; Huang and Trussell, 2008; Ford et al., 2015; Sierksma and Borst, 2017). Whole-cell recordings were made at the mouse calyx of Held, and presynaptic $\mathrm{Na}^{+}$changes during AP firing were assayed using two-photon laser scanning 


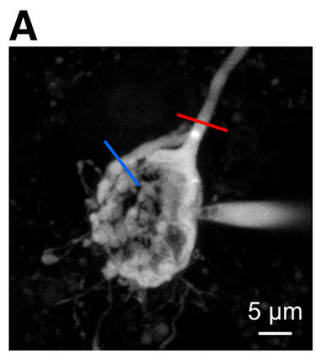

E

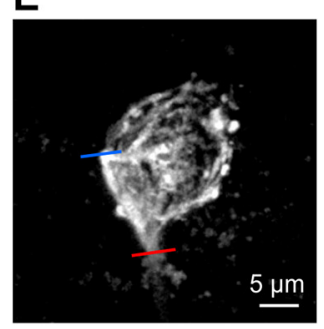

B

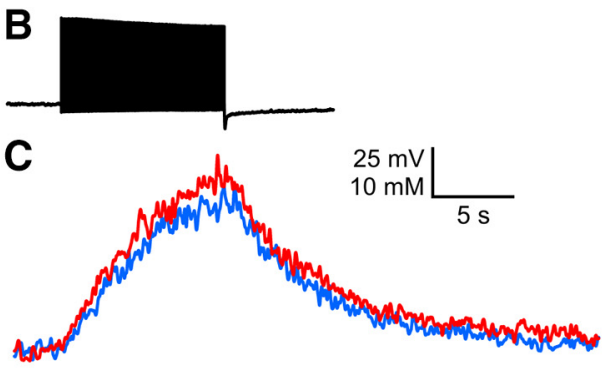

$F$

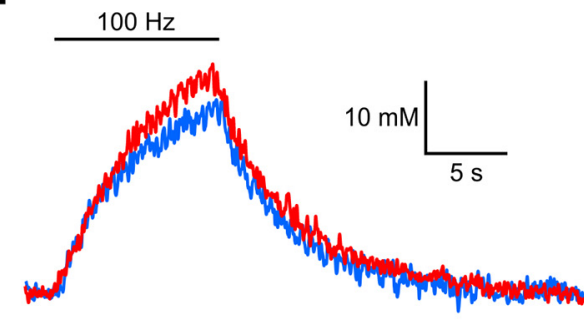

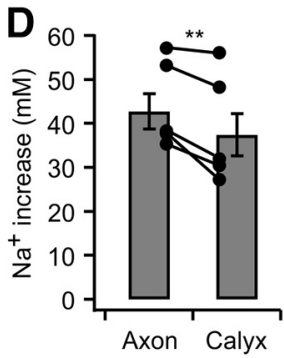

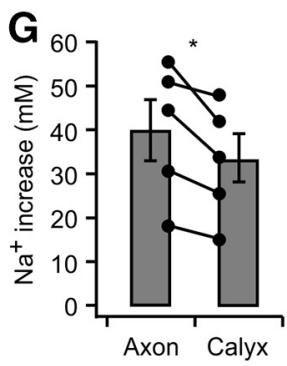

Figure 1. Presynaptic spikes control $\mathrm{Na}^{+}$concentration. $\boldsymbol{A}$, Maximum intensity montage of a P11 calyx of Held recorded using two-photon microscopy at $32^{\circ} \mathrm{C}$. The cell was filled with $\mathrm{SBFI}$ and Alexa Fluor 594, while the Alexa Fluor 594 signal is displayed. $\boldsymbol{B}$, Spikes were evoked at $100 \mathrm{~Hz}$ for $10 \mathrm{~s}$ by afferent fiber stimulation. $\boldsymbol{C}$, Corresponding Na ${ }^{+}$increases were detected at both the preterminal axon heminode (red) and calyceal terminal (blue). $\boldsymbol{D}$, Summary plot of cytosolic $\mathrm{Na}^{+}$increase at the axon and terminal in $\mathrm{P} 8-\mathrm{P} 12$ calyces at $32^{\circ} \mathrm{C}$. $\boldsymbol{E}, \boldsymbol{F}$, Similar to $\boldsymbol{A}, \boldsymbol{C}$, while a P14 calyx was recorded at $37^{\circ} \mathrm{C}$. G, Summary plot of cytosolic $\mathrm{Na}^{+}$increase at the axon and terminal in P13-P16 calyces at $35-37^{\circ} \mathrm{C}$; ${ }^{*} p<0.05,{ }^{* *} p<0.01$. Error bars, $\pm \mathrm{SEM}$.

microscopy (Fig. 1). $\mathrm{Na}^{+}$indicator SBFI (1 mM) and the volume marker Alexa Fluor $594(15 \mu \mathrm{M})$ were loaded via patch pipettes. Calyces with a complete heminode were used to monitor the change in $\left[\mathrm{Na}^{+}\right]$at different locations under line-scans and frame-scans (Fig. 1A). The presynaptic $\left[\mathrm{Na}^{+}\right]$in the resting state was $15.8 \pm 2.1 \mathrm{~mm}(n=4)$, which is similar to previous estimations in neuron and non-neuronal cells (Huang and Trussell, 2014; Meyer et al., 2019). Upon 10-s stimulation at $100 \mathrm{~Hz}, \mathrm{Na}^{+}$ accumulated into the whole calyx terminal (Fig. $1 B, C$ ). The $\mathrm{Na}^{+}$ rise and decay kinetics at axon heminode and calyceal terminal overlapped, while the $\left[\mathrm{Na}^{+}\right]$increase at the calyceal terminal $(37.4 \pm 4.8 \mathrm{~mm})$ was slightly smaller than that of at the axon heminode (42.7 $\pm 4.0 \mathrm{~mm} ; p=0.009, n=6)$. These experiments were done in prehearing (P8-P12) calyces at $32^{\circ} \mathrm{C}$. Previous studies showed that temperature influences AP waveform and thus the $\mathrm{Na}^{+}$influx (Kushmerick et al., 2006) and $\mathrm{Na}^{+}$ extrusion through $\mathrm{Na}^{+} / \mathrm{K}^{+}$-ATPase (Kim et al., 2007). We then repeated the $\mathrm{Na}^{+}$imaging experiment in calyces of hearing $(\mathrm{P} 13-\mathrm{P} 16)$ mice at $35-37^{\circ} \mathrm{C}$ (Fig. 1E-G). Similar results were obtained. The $\left[\mathrm{Na}^{+}\right]$increased by $32.2 \pm 5.6 \mathrm{~mm}$ at the calyceal terminal and $39.2 \pm 6.8 \mathrm{~mm}$ at the heminode $(p=0.04, n=5$; Fig. $1 G)$. Therefore, spike activity substantially increases the cytosolic $\mathrm{Na}^{+}$concentration in both axon heminode and presynaptic terminal of both prehearing and hearing mice at physiological temperature.

\section{Presynaptic $\mathrm{Na}^{+}$regulates glutamatergic transmission}

The previous study showed that presynaptic cytosolic $\mathrm{Na}^{+}$promotes vesicular glutamate uptake and increases miniature EPSC (mEPSC) amplitude (Huang and Trussell, 2014). Here, we performed simultaneous presynaptic and postsynaptic whole-cell recordings to examine how presynaptic $\mathrm{Na}^{+}$influences APdriven synaptic transmission. We dialyzed the cytosolic contents of presynaptic calyces and simultaneously measured AMPA receptor-mediated EPSCs in MNTB principal neurons in the whole-cell mode. The calyces were recorded with pipette solutions containing 0,10 , or $40 \mathrm{~mm} \mathrm{Na}^{+}$; $5 \mathrm{~mm}$ glutamate was added in the presynaptic solutions to maintain cytosolic glutamate
(Ishikawa et al., 2002; Huang and Trussell, 2014). Pairs of presynaptic APs (10-ms intervals) were evoked every 15-20 s by afferent fiber stimulation, and the resulting EPSCs were continuously recorded (Fig. 2). Immediately after presynaptic break-in to whole-cell mode, we observed no difference in EPSC amplitude among different $\mathrm{Na}^{+}$concentrations $(p=0.49$, one-way ANOVA). With the $10 \mathrm{mM} \mathrm{Na}^{+}$solution presynaptically, the EPSC amplitude remained unchanged over $20 \mathrm{~min}$ of recording $(104 \pm 2 \% ; p=0.16, n=6)$. When the calyceal terminals were broken into $\mathrm{Na}^{+}$-free pipette solution, the EPSC amplitude gradually declined by $23 \pm 4 \%$ over the 20 - min period $(p=0.003$, $n=5)$, whereas increasing the presynaptic $\left[\mathrm{Na}^{+}\right]$to $40 \mathrm{~mm}$ induced a $39 \pm 8 \%$ increase in the EPSC amplitude $(p=0.002$, $n=8$; Fig. $2 B, C$ ). When normalized to the values observed immediately after break-in, the EPSC amplitude was clearly smaller in the $\mathrm{Na}^{+}$-free solution than in $10 \mathrm{mM} \mathrm{Na}^{+}(p=0.0001)$ and higher in $40 \mathrm{~mm} \mathrm{Na}^{+}$compared with $10 \mathrm{mM} \mathrm{Na}^{+}(p=0.003$, unpaired $t$ test; Fig. 2C). The presynaptic AP amplitudes remained stable over the recording period in all conditions (Fig. $2 A$ ), presumably because $\mathrm{Na}^{+}$dialysis is much faster than its function on vesicular glutamate transport (Goh et al., 2011; Xue et al., 2013). Since the change in $\mathrm{Na}^{+}$is restricted to the nerve terminal and does not affect the postsynaptic neuron, these data indicate that the changes in EPSC amplitude reflected an alteration in presynaptic glutamate release. No apparent change of the paired-pulse ratio (Fig. 2D) was observed in each group, suggesting that the change in EPSC amplitude is unlikely caused by the change in the presynaptic release probability.

\section{$\mathrm{Na}^{+}$-dependent regulation of synaptic transmission is not due to change in AP waveform}

Intracellular $\mathrm{Na}^{+}$concentration influences the $\mathrm{Na}^{+}$driving force, thus affecting AP waveform, $\mathrm{Ca}^{2+}$ influx, and fusion of synaptic vesicles. We then used 1-ms depolarizing pulses from -80 to $+10 \mathrm{mV}$ to mimic the presynaptic AP and trigger glutamate release (Fig. 3). $\mathrm{Ca}^{2+}$ currents were not different in all groups ( $p=0.89$, one-way ANOVA) and remained stable over the recording period in all conditions $(p=0.46$, two-way 
A $0 \mathrm{mM} \mathrm{Na}^{+}$
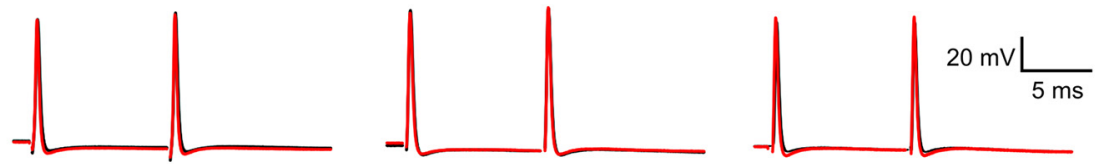

\section{B}
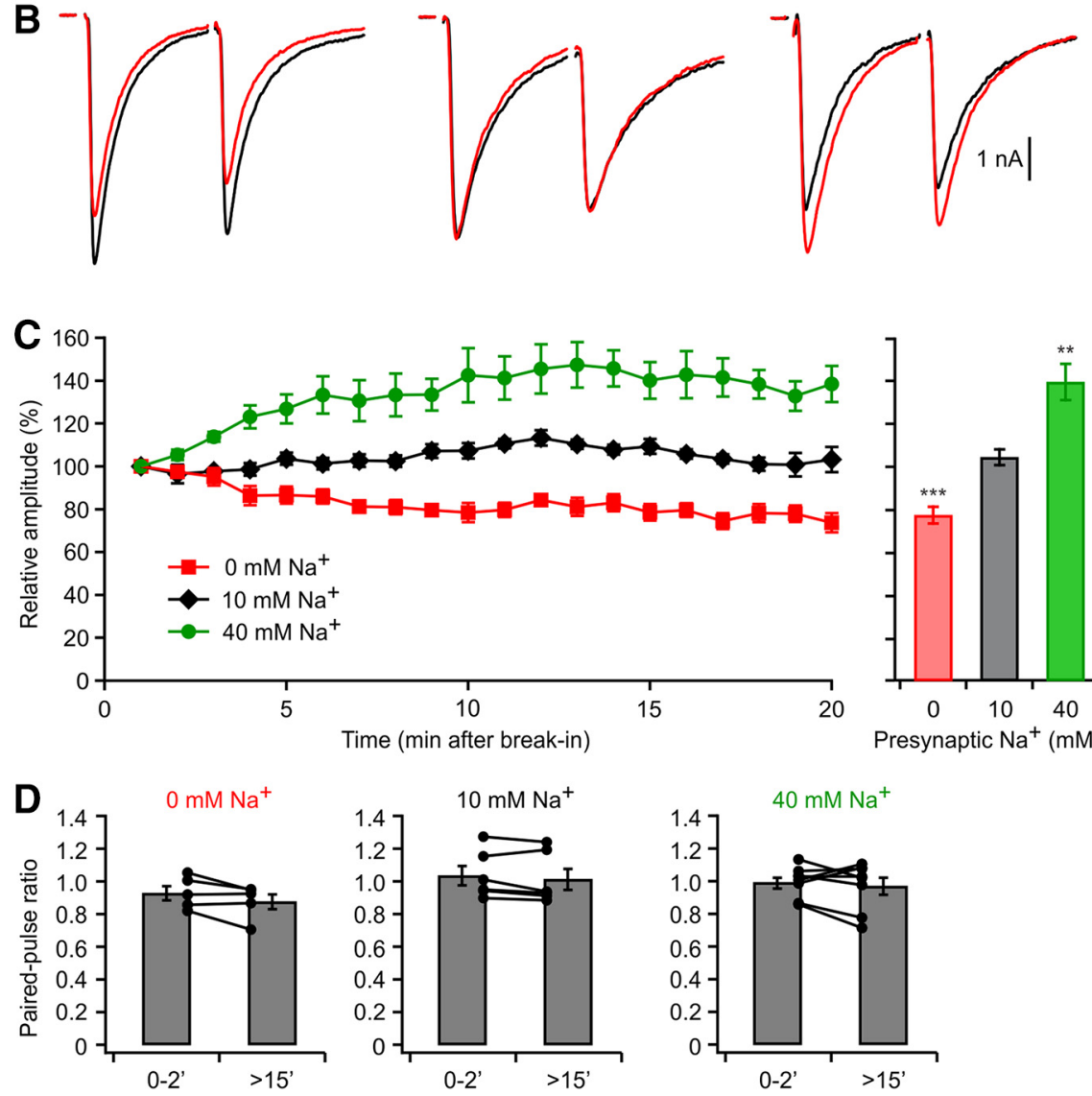

Figure 2. Presynaptic $\mathrm{Na}^{+}$regulates the EPSC amplitude. $A$, Pairs of presynaptic APs induced by afferent fiber stimulation when $0 \mathrm{~mm}$ (left), $10 \mathrm{~mm}$ (middle), or $40 \mathrm{~mm}$ (right) $\mathrm{Na}^{+}$was present in the presynaptic pipette solution. Traces recorded within 2 min of break-in (black) and after $15 \mathrm{~min}$ (red) of recording are superimposed. $\boldsymbol{B}$, Postsynaptic currents in response to the presynaptic APs. $\boldsymbol{C}$, left, Time course of the normalized amplitudes of the first EPSC during paired-pulse recordings. Each point represents the average of 1-min recordings. Right, Relative amplitudes of the first EPSC after 15-min dialysis of the calyces with different $\mathrm{Na}^{+}$concentrations. Amplitudes were normalized to the amplitudes measured within 2 min of break-in. $\boldsymbol{D}$, Presynaptic $\mathrm{Na}^{+}$does not affect the paired-pulse ratio. Statistical significance was assessed using a two-tailed, paired Student's $t$ test; ${ }^{* *} p<0.01,{ }^{* * *} p<0.001$. Error bars, \pm SEM.

ANOVA; Fig. 3A). While the EPSC amplitude remained relatively stable over $20 \mathrm{~min}$ of recording when the presynaptic solution contained $10 \mathrm{mM} \mathrm{Na}^{+}(95 \pm 2 \% ; p=0.06, n=5)$, the EPSC amplitude gradually declined by $20 \pm 3 \%(p=0.002, n=5)$ with the $\mathrm{Na}^{+}$-free solution and increased by $32 \pm 4 \%$ with $40 \mathrm{~mm}$ $\mathrm{Na}^{+}(p=0.0002, n=5$; Fig. 3B,C). No change in the paired-pulse ratio (Fig. $3 D$ ) was observed in any group. This result was similar to that of the AP-triggered release, confirming that the presynaptic $\mathrm{Na}^{+}$-induced change in EPSC amplitude is not due to changes in AP waveform and $\mathrm{Ca}^{2+}$ influx.

Presynaptic $\mathrm{Na}^{+}$does not affect the synaptic vesicle pool or release probability

We next studied the mechanisms of presynaptic $\mathrm{Na}^{+}$-dependent regulation of glutamatergic synaptic transmission. Measurement of $\mathrm{C}_{\mathrm{m}}$ allows direct detection of exocytosis of synaptic vesicles at the calyx of Held with high temporal resolution (Sun

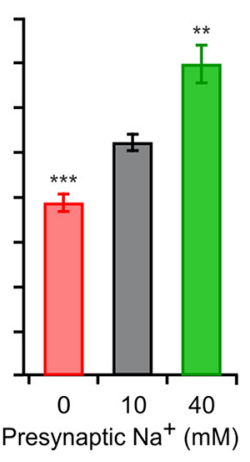

and $\mathrm{Wu}, 2001)$. Typically, a 1-ms depolarization from -80 to $+10 \mathrm{mV}$ can elicit a $\mathrm{Ca}^{2+}$ influx and capacitance change $\left(\Delta \mathrm{C}_{\mathrm{m}}\right)$ is equivalent to a single $\mathrm{AP}$, while a 30 -ms step depolarization is sufficient to deplete the whole readily releasable pool at calyceal terminals (Wu and Borst, 1999; Fedchyshyn and Wang, 2005). We found the $\Delta \mathrm{C}_{\mathrm{m}}$ evoked by $1-$ or $30-\mathrm{ms}$ step depolarization showed no difference across the different $\left[\mathrm{Na}^{+}\right]$groups $(p=$ 0.63 and $p=0.81$, respectively, ANOVA test; Fig. 4). Release probability, defined as the ratio of single AP-evoked $\Delta \mathrm{C}_{\mathrm{m}}$ by the readily releasable pool, was not different among these groups $(p=0.39)$. These data suggest that the presynaptic $\left[\mathrm{Na}^{+}\right]$ does not affect the presynaptic readily releasable pool size or release probability.

Presynaptic $\mathrm{Na}^{+}$controls vesicular glutamate content

We next examined whether presynaptic $\mathrm{Na}^{+}$regulates vesicular glutamate content. Recent studies showed that synaptic vesicles undergoing spontaneous and evoked fusion may be derived from different pools (Fredj and Burrone, 2009; Chanaday and Kavalali, 2018). We recorded the amplitude of asynchronous EPSCs (aEPSCs) in response to single APs, since evoked synchronous release and asynchronous release share the same set of vesicles (Kaeser and Regehr, 2014). Single AP-triggered aEPSCs were induced by substituting extracellular $\mathrm{Ca}^{2+}$ with $\mathrm{Sr}^{2+}$ and recorded in the postsynaptic MNTB neurons (Fig. 5). Immediately after presynaptic break-in to whole-cell mode (within $2 \mathrm{~min}$ ), the aEPSCs showed no significant difference in amplitude in any of the groups $(p=0.20$, one-way ANOVA test). With a $10 \mathrm{~mm}$ presynaptic $\mathrm{Na}^{+}$solution, the aEPSC amplitude remained stable for over $10 \mathrm{~min}$ (98 \pm $2 \% ; p=0.50, n=5)$. The aEPSC amplitude was significantly reduced by $15 \pm 2 \%(p=0.003 ; n=5)$ with $0 \mathrm{~mm}$ $\mathrm{Na}^{+}$and increased by $17 \pm 2 \%(p=0.0005 ; n=6)$ with $40 \mathrm{~mm} \mathrm{Na}^{+}$ presynaptically. We also tested whether 8 -Br-cAMP, a cell membrane-permeant cAMP analog that activates HCN channels and increases presynaptic $\mathrm{Na}^{+}$levels (Huang and Trussell, 2014), affects the amplitude of aEPSC. To avoid the possible PKA phosphorylation of AMPA receptor (Esteban et al., 2003), $10 \mu \mathrm{M} \mathrm{H}-89$ was added into the pipette solution to inhibit kinase activation. Bath application of 8-Br-cAMP increased the aEPSC amplitude by $19 \pm 2 \%(p=0.0006 ; n=6)$. The difference in aEPSC amplitude suggested that alteration of the presynaptic $\mathrm{Na}^{+}$level affected vesicular glutamate loading for both spontaneous and evoked release.

Presynaptic $\mathrm{Na}^{+}$is required for reliable signal transmission High-frequency signals of each globular bushy cell reliably transmit to a target MNTB principal neuron through the calyx of Held synapse, with few or no failures (Mc Laughlin et al., 2008; 
Lorteije et al., 2009). We next asked whether the cytosolic $\mathrm{Na}^{+}$-dependent modulation of EPSCs affects the reliability of signal transmission from the presynaptic calyx of Held to the postsynaptic MNTB neuron. Paired presynaptic and postsynaptic APs were recorded in response to calyceal fiber stimulation. Fiber stimuli at $200-\mathrm{Hz}$ reliably evoked APs in the presynaptic terminals during the whole-cell recordings in 0,10 , and $40 \mathrm{mM} \mathrm{Na}^{+}$conditions (Fig. 6A). Immediately after presynaptic break-in to whole-cell mode, most of the triggered presynaptic spikes correlated with postsynaptic spikes in the MNTB neurons, with only a few failures in the late phase of the stimulation (Fig. 6B). When the calyceal terminals were dialyzed with a $10 \mathrm{mM} \mathrm{Na}^{+}$solution, no significant difference in the reliability of postsynaptic AP was observed over recording durations of $>10 \mathrm{~min}(p=0.46$, $n=8$; Fig. $6 B-E$ ). The probability of failure increased gradually with time when the presynaptic solution became $\mathrm{Na}^{+}$ free. After $10 \mathrm{~min}$ of presynaptic dialysis, the reliability was greatly reduced, and presynaptic release in the latter part of the stimulus train was unable to drive postsynaptic APs $(p=0.01, n=6$; Fig. $6 B-E)$. In contrast, when the calyceal terminal was dialyzed with a $40 \mathrm{~mm}$ $\mathrm{Na}^{+}$solution, presynaptic spikes transmitted to the postsynaptic neuron showed less failures and higher firing probability after repeated stimuli trains, indicating that higher presynaptic $\mathrm{Na}^{+}$level enhanced reliable synaptic transmission at the calyx of Held synapse $(p=0.004, n=8$; Fig. $6 B-E)$. It was notable that, for those events where the MNTB principal neuron failed to fire an AP, a subthreshold EPSP was observed, indicating that the presynaptic spikes caused reliable release, but the synaptic current was not large enough to trigger a postsynaptic spike. Thus, the presynaptic $\mathrm{Na}^{+}$ level facilitates vesicular glutamate uptake and eventually boosts reliable synaptic transmission.

\section{NHE activity promotes synaptic transmission and signaling reliability}

Synaptic vesicles express NHE, which converts the $\mathrm{pH}$ gradient into an electrical potential required by the VGluT and promotes synaptic vesicle filling with glutamate (Goh et al., 2011; Huang and Trussell, 2014; Preobraschenski et al., 2014). Since presynaptic spikes substantially increase the presynaptic $\mathrm{Na}^{+}$level, we asked whether NHE activity is required in maintaining the highly reliable synaptic transmission. Under perforated patch-clamp recordings, we were able to record EPSCs and postsynaptic APs over a long duration $(>30 \mathrm{~min})$. Prolonged presynaptic fiber stimulation evoked reliable and stable EPSCs. Incubating EIPA

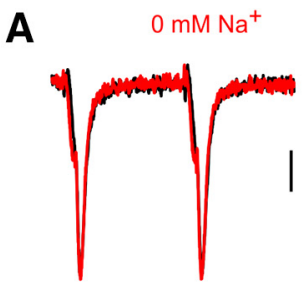

$\mathbf{B}$
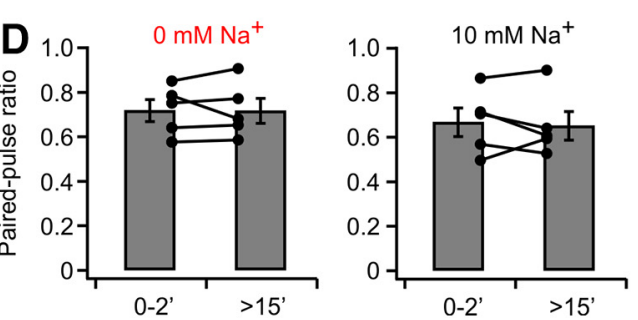

$10 \mathrm{mM} \mathrm{Na}^{+}$
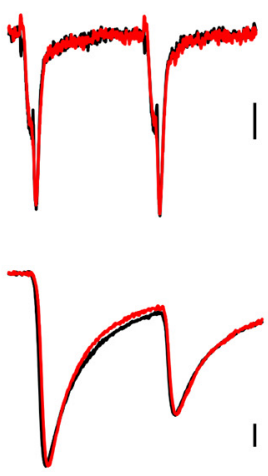

$40 \mathrm{mM} \mathrm{Na}^{+}$
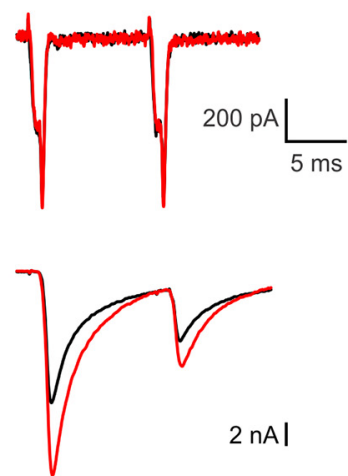
(10 mV when $0 \mathrm{~mm}$ (left), $10 \mathrm{~mm}$ (middle), or $40 \mathrm{~mm}$ (right) $\mathrm{Na}^{+}$was present in the presynaptic pipette solutions.

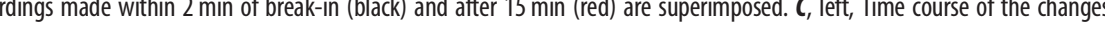
min of recordings with different presynaptic $\mathrm{Na}^{+}$concentrations. Amplitudes were normalized to the amplitudes measured within 2 min of break-in. $\boldsymbol{D}$, Presynaptic $\mathrm{Na}^{+}$does not affect the paired-pulse ratio in response to presynaptic depolarization. Statistical significance was assessed using a two-tailed, paired Student's $t$ test; ${ }^{* *} p<0.01,{ }^{* * *} p<0.001$. Error bars, \pm SEM.

$(100 \mu \mathrm{M})$, an NHE-specific blocker, reduced the EPSC amplitude to $54.8 \pm 6.8 \%(p=0.003, n=5$; Fig. $7 A, B)$. Meanwhile, the postsynaptic firing started to fail after 6 min incubation of EIPA; the overall firing probability reduced to $21.2 \pm 8.6 \%(p=0.003, n=4$; Fig. $7 C, D)$. A subthreshold EPSP was always observed when the MNTB neuron failed to fire an AP, indicating that the presynaptic spikes invaded into the terminals although the glutamate contents were not enough to trigger a postsynaptic spike. Decrease of both EPSC amplitude and firing probability confirms that $\mathrm{Na}^{+}$and NHE activity are required in maintaining reliable synaptic signaling at high frequency.

\section{Discussion}

In this study, we found a substantial accumulation of $\mathrm{Na}^{+}$in the presynaptic terminal during high-frequency signaling. The presynaptic $\mathrm{Na}^{+}$facilitated glutamate uptake into synaptic vesicles 
A

$0 \mathrm{mM} \mathrm{Na}^{+}$

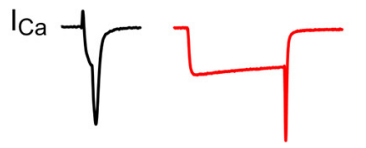

B
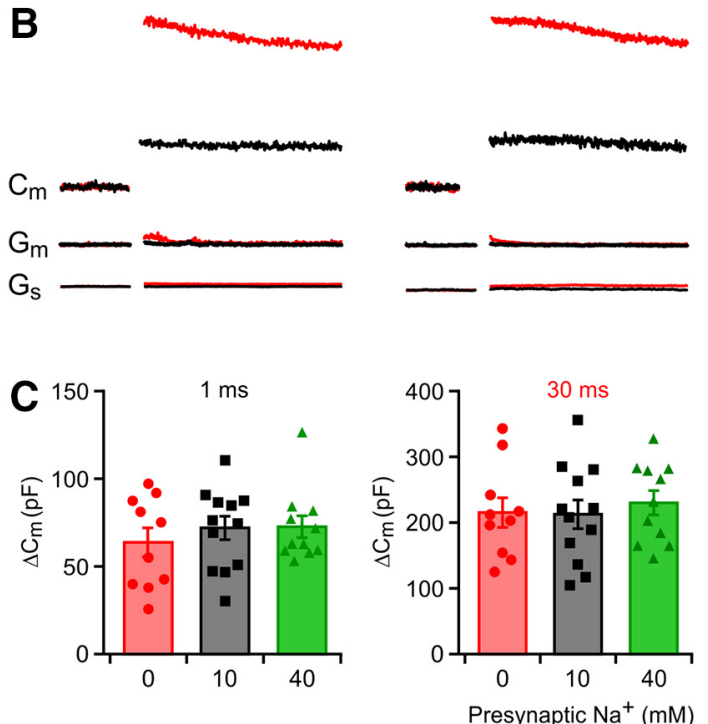

$40 \mathrm{mM} \mathrm{Na}^{+}$
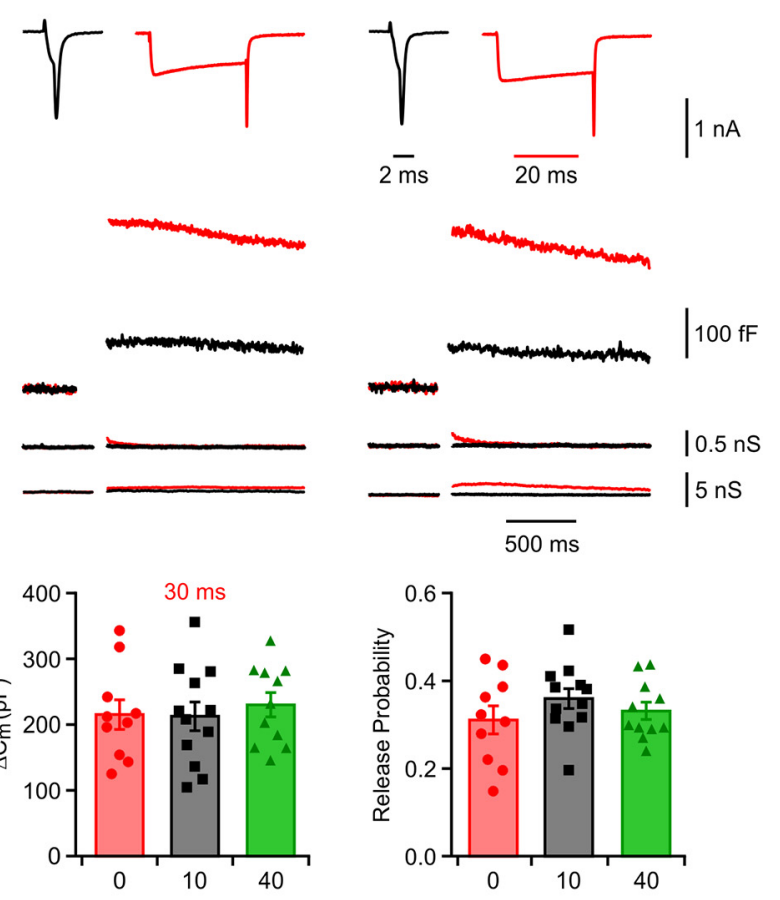

Figure 4. Presynaptic $\mathrm{Na}^{+}$does not affect the readily releasable pool size or release probability. $\boldsymbol{A}, \boldsymbol{B}$, Sampled presynaptic $\mathrm{Ca}^{2+}$ currents $\left(\mathrm{I}_{\mathrm{Ca}} ; \boldsymbol{A}\right)$ and $\mathrm{C}_{\mathrm{m}}$ responses $(\boldsymbol{B})$ induced by a 1 -ms (black) or 30-ms (red) depolarizations from -80 to $+10 \mathrm{mV}$ with presynaptic pipette solutions containing $0 \mathrm{~mm}$ (left), $10 \mathrm{~mm}$ (middle), or $40 \mathrm{~mm}$ (right) $\mathrm{Na}^{+}$. The corresponding membrane conductance $\left(G_{m}\right)$ and series conductance $\left(G_{s}\right)$ are shown to confirm the recording stability. $C$, Group data show that the presynaptic $\left[\mathrm{Na}^{+}\right]$does not affect the $C_{m}$ responses or release probability. Error bars, \pm SEM.
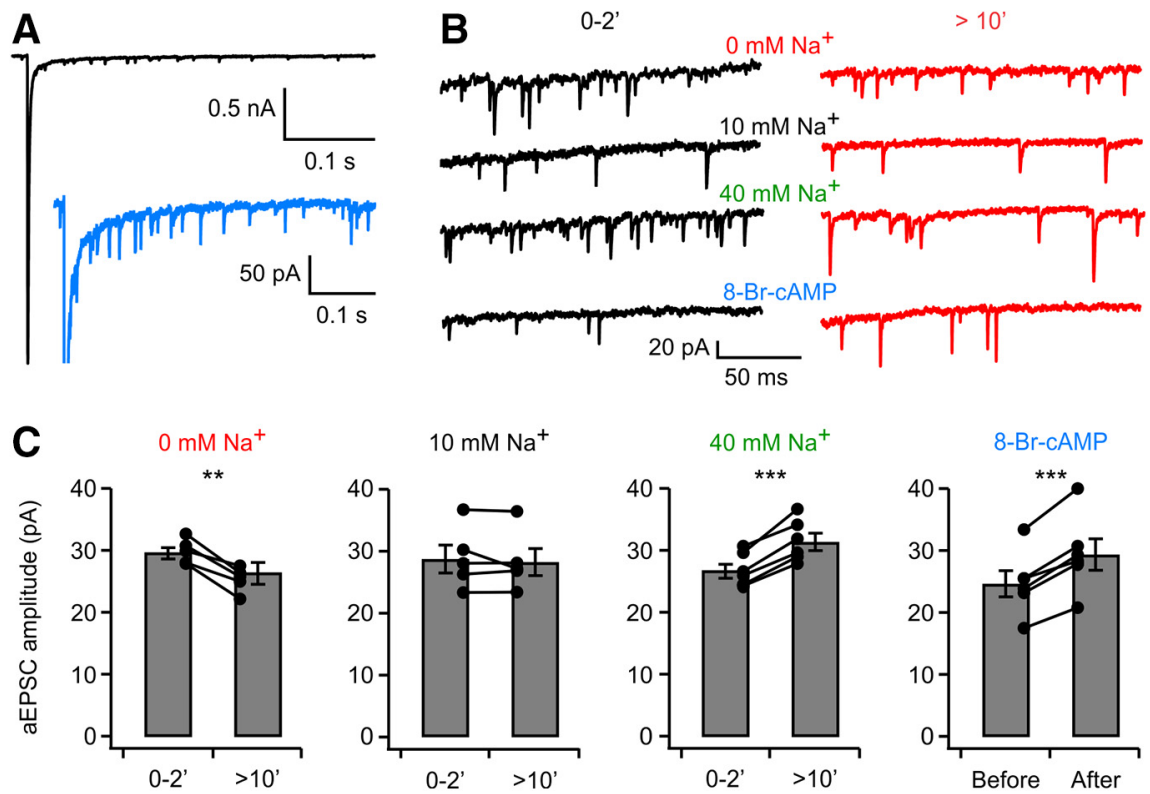

Figure 5. Presynaptic $\mathrm{Na}^{+}$regulates aEPSC amplitude. $\boldsymbol{A}$, Example trace of prolonged period of asynchronous release (aEPSCS) followed by the initial fast EPSC evoked by a single presynaptic stimulation. The insert shows an expanded trace of the asynchronous release (blue). $\boldsymbol{B}$, Example traces of asynchronous events within $2 \mathrm{~min}$ (black) and $>10 \mathrm{~min}$ (red) after presynaptic break-in to 0,10 , or $40 \mathrm{~mm} \mathrm{Na}^{+}$pipette solution. The bottom traces show the recordings before (black) and $>10$ min after (red) application of 8-Br-CAMP; $10 \mu \mathrm{M} \mathrm{H}-89$ was present in the postsynaptic pipette solution to inhibit 8-BrcAMP-induced kinase activation. C, Bar graphs of the change in aEPSC amplitude when presynaptic pipette solution, as well as before and after application of 8-Br-cAMP. Statistical significance was assessed using a two-tailed paired Student's $t$ test; ${ }^{* *} p<0.01,{ }^{* * *} p<0.001$. Error bars, \pm SEM. without changing the readily releasable pool size or release probability. Our results reveal a mechanism by which APdriven $\mathrm{Na}^{+}$influx controls the strength of synaptic transmission by modulating vesicular content. During high-frequency synaptic signaling, when large amounts of glutamate are released, $\mathrm{Na}^{+}$accelerates vesicle replenishment and sustains synaptic transmission, representing a novel cellular mechanism that supports reliable synaptic transmission at high-frequency in the central nervous system.

Glutamate is the principal excitatory neurotransmitter in the brain and is involved in most aspects of brain function (Mayer and Armstrong, 2004). The concentrating of glutamate into synaptic vesicles involves plasma membrane excitatory amino acid transporters (EAATs) and VGluTs. EAATs are high-affinity, $\mathrm{Na}^{+}$coupled transporters that recycle glutamate and glutamine from the extracellular space to the cytoplasm; the function of these transporters has been extensively studied (Amara and Fontana, 2002). VGluTs transport glutamate from the cytoplasm into synaptic vesicles for subsequent release by exocytosis, but we still know very little about the basic mechanisms that regulate vesicular glutamate transport, in part because classical biochemical approaches have limitations in revealing the complex ionic basis for the loading of neurotransmitter into vesicles while electrophysiological methods are hard to be applied to the study of synaptic organelles (Balmer and Trussell, 2016). Glutamate receptors are not saturated by synaptically released glutamate (Ishikawa et al., 2002; Conti and Lisman, 2003; Sargent et al., 2005); therefore, changes in the amount of glutamate released per synaptic vesicle have the potential to control synaptic strength. The fusion of a single vesicle induces a quantal response, and the size of the quantum varies at most synapses. The variation of mEPSC amplitude (quantal size) is determined by vesicular glutamate concentration rather than vesicle volume ( $\mathrm{Wu}$ et al., 2007), indicating a crucial role of vesicular glutamate uptake in determining synaptic strength. Vesicular transporters drive neurotransmitter accumulation using the energy of the proton electrochemical gradient $\left(\Delta \mu_{\mathrm{H}+}\right)$ produced by the vacuolar $\mathrm{H}^{+}$ATPase (V-ATPase; Edwards, 2007). The $\Delta \mu_{\mathrm{H}+}$ reflects both electrical potential $(\Delta \psi)$ and chemical concentration gradient $(\Delta \mathrm{pH})$. Previous studies demonstrated that glutamate uptake into synaptic vesicles by the VGluT is dependent mostly on $\Delta \psi$ rather than $\Delta \mathrm{pH}$ (Maycox et al., 1988; 
A

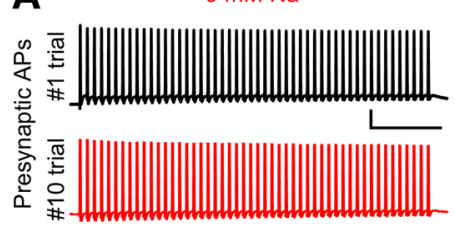

B
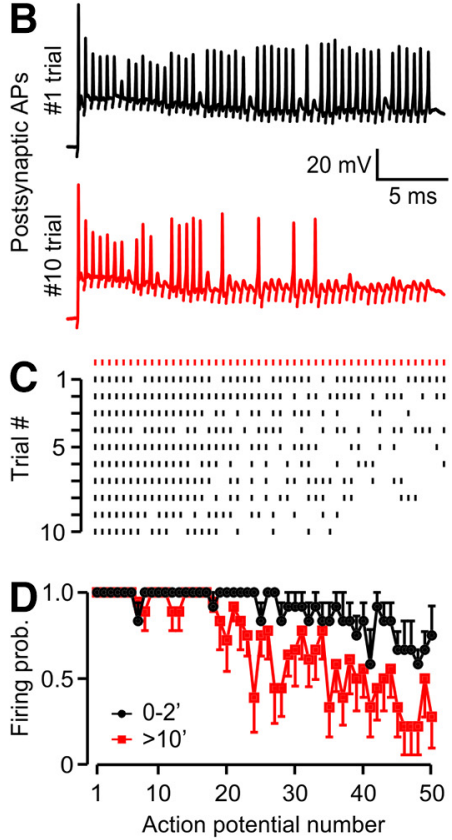
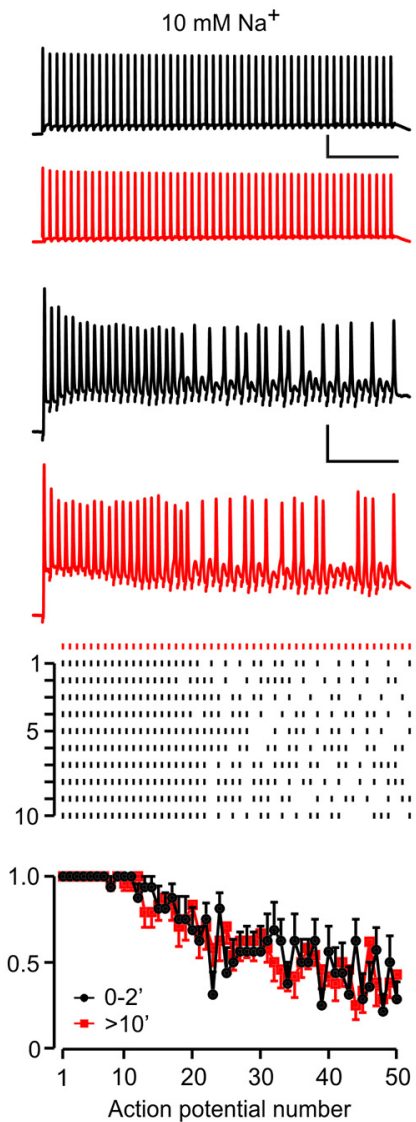
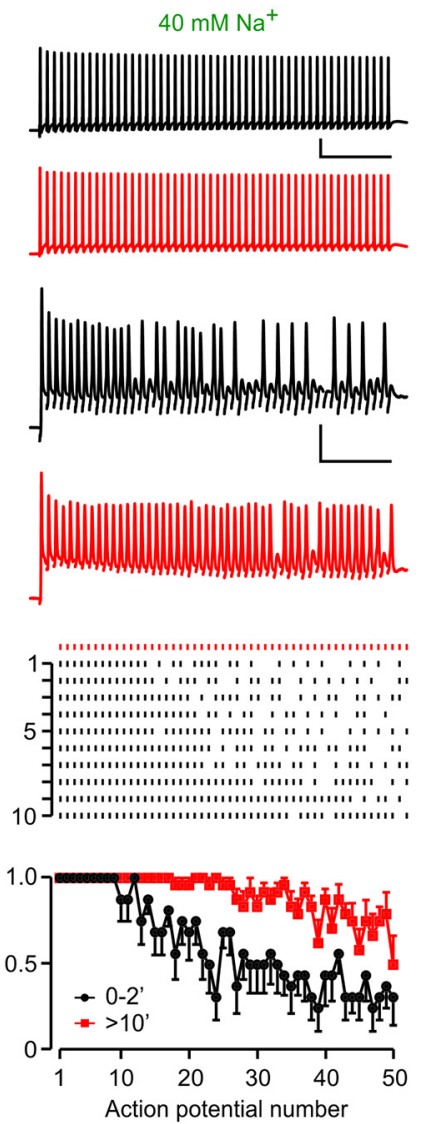
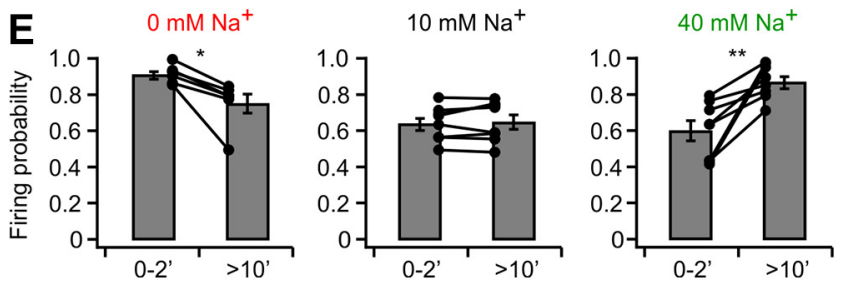

Figure 6. Presynaptic $\mathrm{Na}^{+}$level contributes to reliable synaptic transmission. $A$, Example traces of 50 presynaptic APs immediately (black) and 10 min (red) after break-in with 0 , 10 , and $40 \mathrm{~mm} \mathrm{Na}^{+}$in the presynaptic pipette solution. APs were evoked by $200-\mathrm{Hz}$ afferent fiber stimulation. B, Postsynaptic spiking in MNTB principal neurons in response to the presynaptic firing in $\boldsymbol{A}$. C, Raster plots of spikes evoked by 200-Hz, 250-ms stimulus trains repeated with 60-s intervals. Presynaptic spikes are shown at the top in red. D, Summary plots of average postsynaptic firing probability in response to 50 presynaptic APs at $200 \mathrm{~Hz}$. E, Overall change in the postsynaptic firing probability between the first $2 \mathrm{~min}$ and after $10 \mathrm{~min}$, with 0,10 , or $40 \mathrm{~mm}$ presynaptic $\mathrm{Na}^{+}$. Statistical significance was assessed using a two-tailed paired Student's $t$ test; ${ }^{*} p<0.05,{ }^{* *} p<0.01$. Error bars, \pm SEM.

Tabb et al., 1992). However, glutamate entry acidifies synaptic vesicles and reduces the capacity of $\mathrm{V}$-ATPase to create the $\Delta \psi$ required for VGluT activity, thereby stalling the uploading of glutamate. Recent work showed that synaptic vesicles express a $\mathrm{Na}^{+}\left(\mathrm{K}^{+}\right) / \mathrm{H}^{+}$monovalent cation exchanger (NHE) activity that converts $\Delta \mathrm{pH}$ into $\Delta \psi$ and promotes synaptic vesicle filling with glutamate. Manipulating presynaptic $\left[\mathrm{K}^{+}\right]$changed the mEPSC amplitude even when the glutamate supply was constant, indicating that the synaptic vesicle NHE regulates glutamate release and synaptic transmission (Goh et al., 2011). Another study showed that $\mathrm{K}^{+}$ facilitates glutamate transport by directly acting on VGluT binding sites, and confirmed that the NHE is responsible for $\mathrm{Na}^{+}$effects on vesicular glutamate uptake (Preobraschenski et al., 2014). Indeed, presynaptic $\mathrm{Na}^{+}$is more potent than $\mathrm{K}^{+}$in facilitating glutamate uptake and a small change in presynaptic $\left[\mathrm{Na}^{+}\right]$affects the mEPSC amplitude even in the presence of normal $\left[\mathrm{K}^{+}\right] . \mathrm{Na}^{+}$influx through plasma membrane $\mathrm{HCN}$ channels affects presynaptic $\mathrm{Na}^{+}$concentration, regulates glutamate uptake, and thus controls mEPSC amplitude (Huang and Trussell, 2014). Here, we found that $\mathrm{Na}^{+}$ facilitated synaptic transmission by facilitating glutamate uptake into synaptic vesicles without changing the readily releasable pool size or release probability. The isoform of NHE remains unknown. Recent studies suggest NHE6 is likely the candidate: (1) mass spectrometry experiments showed that NHE6 was recently found in both GABAergic and glutamatergic synaptic vesicles (Grønborg et al., 2010); (2) NHE6 was detected by western blotting on highly purified Synaptic vesicles (Preobraschenski et al., 2014); and (3) NHE6 localized to axonal compartments and was increased in area CA1 of the mouse hippocampus during synaptogenesis (Deane et al., 2013).

$\mathrm{Na}^{+}$channels are expressed in hippocampal mossy fiber boutons (Engel and Jonas, 2005), while the location of $\mathrm{Na}^{+}$channels in the calyx of Held is more complicated (Leão et al., 2005; Ford et al., 2015; Berret et al., 2016; Sierksma and Borst, 2017; Xu et al., 2017). The morphology of the calyceal terminals and the expression of $\mathrm{Na}^{+}$channels undergo dramatic developmental changes around hearing onset. $\mathrm{Na}^{+}$channel is expressed on the calyceal terminals of prehearing rodents (Sierksma and Borst, 2017; Xu et al., 2017) and the $\mathrm{Na}^{+}$currents recorded in calyces 

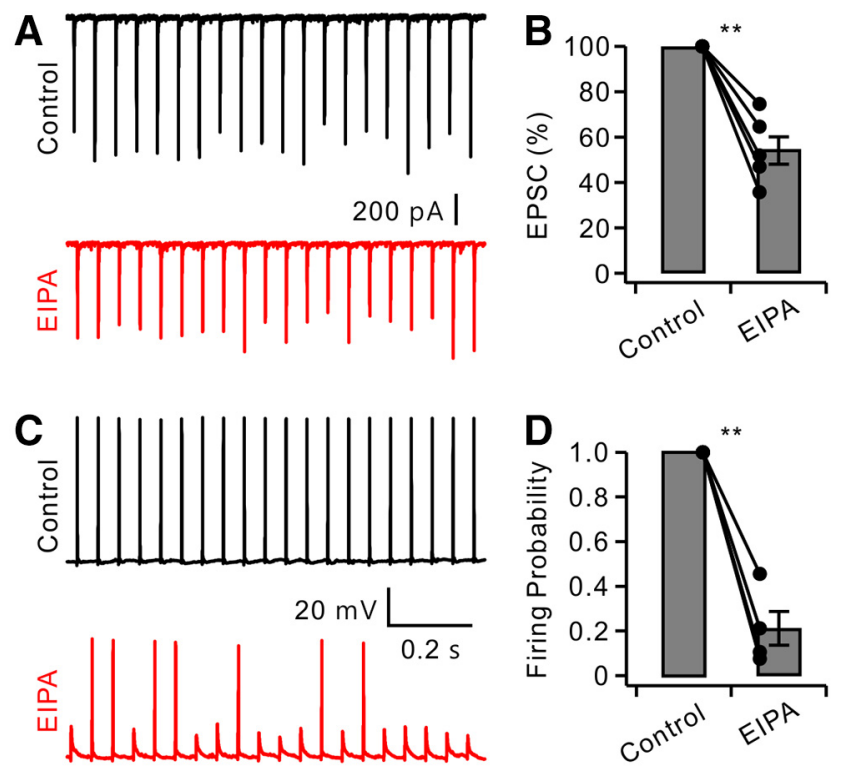

Figure 7. NHE activity is required for reliable synaptic signaling. $\boldsymbol{A}$, Example traces of EPSC recordings before and $10 \mathrm{~min}$ after incubation of $100 \mu \mathrm{m}$ EIPA on 20-Hz presynaptic stimulation. $\boldsymbol{B}$, EIPA decreased EPSC amplitude. $\boldsymbol{C}$, Example traces of postsynaptic AP recordings before and $10 \mathrm{~min}$ after applying EIPA $(100 \mu \mathrm{m})$. D. EIPA reduced the reliability of postsynaptic firing. Statistical significance was assessed using a two-tailed paired Student's $t$ test; ${ }^{* *} p<0.01$. Error bars, \pm SEM.

with incised axon show comparable amplitude (Huang and Trussell, 2008). In more mature animals, $\mathrm{Na}^{+}$channels are more concentrated at the preterminal hemihode region (Ford et al., 2015; Berret et al., 2016; Xu et al., 2017), although lower expression was detected in the calyces of hearing rats (Sierksma and Borst, 2017). Consistently, $30 \%$ of the outside-out patches of P8-P10 calyx have $\mathrm{Na}^{+}$current (Leão et al., 2005), and it decreases to $\sim 10 \%$ in P13-P17 calyx of rat (Berret et al., 2016). We showed here that spike activity efficiently and substantially increased the cytosolic $\mathrm{Na}^{+}$concentration in both axon heminode and presynaptic terminal, the overall $\left[\mathrm{Na}^{+}\right]$reached to 50 mu after $10 \mathrm{~s}$ of $100-\mathrm{Hz}$ spiking (Fig. 1). Our result is comparable to a previous study (Berret et al., 2016). The $\left[\mathrm{Na}^{+}\right]$increase was slightly lower in hearing calyces at $35-37^{\circ} \mathrm{C}$ than in prehearing calyces at $32^{\circ} \mathrm{C}$, presumably due to a developmental change of $\mathrm{Na}^{+}$channel expression and temperature-dependence of AP waveform and $\mathrm{Na}^{+} / \mathrm{K}^{+}$-ATPase activity (Taschenberger and von Gersdorff, 2000; Kushmerick et al., 2006; Kim et al., 2007; Xu et al., 2017). Moreover, the $\mathrm{Na}^{+}$rise and decay kinetics at axon heminode and calyceal terminal overlapped, while $\left[\mathrm{Na}^{+}\right]$ increase at the calyceal terminal was slightly (12\%-18\%) smaller than that of at the axon heminode, presumably due to differential $\mathrm{Na}^{+}$channel distribution. Although $\mathrm{HCN}$ is prominent in controlling the resting $\mathrm{Na}^{+}$concentration, spikes are much more potent in regulating presynaptic $\mathrm{Na}^{+}$accumulation than $\mathrm{HCN}$ channels during activity. Blocking $\mathrm{HCN}$ channels, which took over $10 \mathrm{~min}$ to reach an equilibrated concentration, reduced the resting $\mathrm{Na}^{+}$concentration by $\sim 5 \mathrm{~mm}$ (Huang and Trussell, 2014). The calyx $\left[\mathrm{Na}^{+}\right]$increase on $10 \mathrm{~s}$ of $100-\mathrm{Hz}$ firing (Fig. 1) is five times larger than the overall contribution of HCN channels at resting membrane potentials. Since HCN channels are deactivated by depolarizations during spiking, their contribution to the overall presynaptic cytosolic $\mathrm{Na}^{+}$would be even smaller (Huang and Trussell, 2014). The calyx recorded in brain slices does not fire spontaneously, however, it fires in vivo at frequencies of $71 \pm 11 \mathrm{~Hz}$ in the absence of sound and up to
$352 \pm 34 \mathrm{~Hz}$ with $80-\mathrm{dB}$ tones (Lorteije et al., 2009). Therefore, the presynaptic $\left[\mathrm{Na}^{+}\right]$would be substantially higher in vivo than that of the slice preparations.

Globular bushy cells fire APs reliably and precisely synchronized to sound. High-frequency signals of globular bushy cells are reliably transmitted to the target MNTB neurons through the calyx of Held synapse. Different cellular mechanisms have been established that are important to support neurotransmission at such high rates, including presynaptic ion channels that enable reliable presynaptic spike waveform and calcium influx; a large readily releasable pool, many release sites, and low release probability that enhance the release reliability; and fast kinetics of postsynaptic AMPA-type glutamate receptors that allow fast and faithful transmission to the postsynaptic MNTB neurons (Taschenberger and von Gersdorff, 2000; Taschenberger et al., 2002; Borst and Soria van Hoeve, 2012; Xue et al., 2013). We found that the cytosolic $\mathrm{Na}^{+}$-dependent facilitation of vesicular glutamate uptake contributes to the reliability of synaptic transmission at the calyceal synapse. The reliability of AP propagation from calyx to MNTB dropped to $\sim 50 \%$ after a few spikes (Fig. 6), which is much lower than that in in vivo conditions (Mc Laughlin et al., 2008; Lorteije et al., 2009). This could be explained by the lower presynaptic $\left[\mathrm{Na}^{+}\right]$ in slice preparation that calyces do not fire spikes spontaneously. In the intact brain, however, the calyx fires at high frequencies, which would elevate the presynaptic $\left[\mathrm{Na}^{+}\right]$to over $50 \mathrm{~mm}$ (Fig. 1). The elevated $\left[\mathrm{Na}^{+}\right]$facilitates vesicular glutamate transport and the bigger quantal size ensures reliable synaptic transmission. Indeed, increasing the presynaptic $\left[\mathrm{Na}^{+}\right]$to $40 \mathrm{~mm}$ in the slice preparation rescued the reliability of high-frequency transmission (Fig. 6).

The strength of synaptic transmission is determined by the readily releasable vesicle pool, release probability, and quantal size. Although the readily releasable vesicle pool and release probability reflect presynaptic properties, it is generally accepted that the changes in quantal size indicate postsynaptic alterations in neurotransmitter receptor interactions. Our results show that during high-frequency spiking activity, intracellular $\mathrm{Na}^{+}$is elevated in the terminals and altered the quantal size, which provides a novel presynaptic mechanism to control synaptic strength through changes in the concentration of transmitter in synaptic vesicles without changing the readily releasable vesicle pool or release probability. Since this presynaptic change of synaptic transmission does not affect the paired-pulse ratio, our results suggest caution in interpreting studies which use pairedpulse ratio to determine presynaptic or postsynaptic changes. This activity-dependent modulation of vesicular content provides a novel mechanism of synaptic plasticity, and these findings have potentially universal implications for the regulation of synaptic efficacy in the central nervous system, especially for neurons that fire high-frequency spikes.

\section{References}

Amara SG, Fontana AC (2002) Excitatory amino acid transporters: keeping up with glutamate. Neurochem Int 41:313-318.

Balmer TS, Trussell LO (2016) Quantum disentanglement: electrical analysis of the complex roles of ions in filling vesicles with glutamate. Neuron 90:667-669.

Barnes-Davies M, Forsythe ID (1995) Pre- and postsynaptic glutamate receptors at a giant excitatory synapse in rat auditory brainstem slices. J Physiol 488:387-406.

Bender KJ, Ford CP, Trussell LO (2010) Dopaminergic modulation of axon initial segment calcium channels regulates action potential initiation. Neuron 68:500-511. 
Berret E, Kim SE, Lee SY, Kushmerick C, Kim JH (2016) Functional and structural properties of ion channels at the nerve terminal depends on compact myelin. J Physiol 594:5593-5609.

Borst JG, Soria van Hoeve J (2012) The calyx of held synapse: from model synapse to auditory relay. Annu Rev Physiol 74:199-224.

Chanaday NL, Kavalali ET (2018) Presynaptic origins of distinct modes of neurotransmitter release. Curr Opin Neurobiol 51:119-126.

Chen C, Regehr WG (1999) Contributions of residual calcium to fast synaptic transmission. J Neurosci 19:6257-6266.

Conti R, Lisman J (2003) The high variance of AMPA receptor- and NMDA receptor-mediated responses at single hippocampal synapses: evidence for multiquantal release. Proc Natl Acad Sci USA 100:4885-4890.

Deane EC, Ilie AE, Sizdahkhani S, Das Gupta M, Orlowski J, McKinney RA (2013) Enhanced recruitment of endosomal $\mathrm{Na}+/ \mathrm{H}+$ exchanger NHE6 into dendritic spines of hippocampal pyramidal neurons during NMDA receptor-dependent long-term potentiation. J Neurosci 33:595-610.

Edwards RH (2007) The neurotransmitter cycle and quantal size. Neuron 55:835-858.

Engel D, Jonas P (2005) Presynaptic action potential amplification by voltage-gated $\mathrm{Na}+$ channels in hippocampal mossy fiber boutons. Neuron 45:405-417.

Esteban JA, Shi SH, Wilson C, Nuriya M, Huganir RL, Malinow R (2003) PKA phosphorylation of AMPA receptor subunits controls synaptic trafficking underlying plasticity. Nat Neurosci 6:136-143.

Farsi Z, Jahn R, Woehler A (2017) Proton electrochemical gradient: driving and regulating neurotransmitter uptake. Bioessays 39:1600240.

Fedchyshyn MJ, Wang LY (2005) Developmental transformation of the release modality at the calyx of Held synapse. J Neurosci 25:4131-4140.

Ford MC, Alexandrova O, Cossell L, Stange-Marten A, Sinclair J, KoppScheinpflug C, Pecka M, Attwell D, Grothe B (2015) Tuning of Ranvier node and internode properties in myelinated axons to adjust action potential timing. Nat Commun 6:8073.

Fredj NB, Burrone J (2009) A resting pool of vesicles is responsible for spontaneous vesicle fusion at the synapse. Nat Neurosci 12:751-758.

Goh GY, Huang H, Ullman J, Borre L, Hnasko TS, Trussell LO, Edwards RH (2011) Presynaptic regulation of quantal size: $\mathrm{K}+/ \mathrm{H}+$ exchange stimulates vesicular glutamate transport. Nat Neurosci 14:1285-1292.

Grønborg M, Pavlos NJ, Brunk I, Chua JJ, Münster-Wandowski A, Riedel D, Ahnert-Hilger G, Urlaub H, Jahn R (2010) Quantitative comparison of glutamatergic and GABAergic synaptic vesicles unveils selectivity for few proteins including MAL2, a novel synaptic vesicle protein. J Neurosci 30:2-12.

Heuser JE, Reese TS (1973) Evidence for recycling of synaptic vesicle membrane during transmitter release at the frog neuromuscular junction. J Cell Biol 57:315-344.

$\mathrm{Hu} \mathrm{H}$, Jonas $\mathrm{P}$ (2014) A supercritical density of $\mathrm{Na}(+)$ channels ensures fast signaling in GABAergic interneuron axons. Nat Neurosci 17:686-693.

Huang H, Trussell LO (2008) Control of presynaptic function by a persistent $\mathrm{Na}(+)$ current. Neuron 60:975-979.

Huang H, Trussell LO (2011) KCNQ5 channels control resting properties and release probability of a synapse. Nat Neurosci 14:840-847.

Huang H, Trussell LO (2014) Presynaptic HCN channels regulate vesicular glutamate transport. Neuron 84:340-346.

Ishikawa T, Sahara Y, Takahashi T (2002) A single packet of transmitter does not saturate postsynaptic glutamate receptors. Neuron 34:613-621.

Kaeser PS, Regehr WG (2014) Molecular mechanisms for synchronous, asynchronous, and spontaneous neurotransmitter release. Annu Rev Physiol 76:333-363.

Kim JH, Sizov I, Dobretsov M, von Gersdorff H (2007) Presynaptic Ca2+ buffers control the strength of a fast post-tetanic hyperpolarization mediated by the alpha3 $\mathrm{Na}(+) / \mathrm{K}(+)$-ATPase. Nat Neurosci 10:196205.

Klingauf J, Kavalali ET, Tsien RW (1998) Kinetics and regulation of fast endocytosis at hippocampal synapses. Nature 394:581-585.

Kushmerick C, Renden R, von Gersdorff H (2006) Physiological temperatures reduce the rate of vesicle pool depletion and short-term depression via an acceleration of vesicle recruitment. J Neurosci 26: 1366-1377.

Leão RM, Kushmerick C, Pinaud R, Renden R, Li GL, Taschenberger H, Spirou G, Levinson SR, von Gersdorff H (2005) Presynaptic Na+ channels: locus, development, and recovery from inactivation at a high-fidelity synapse. J Neurosci 25:3724-3738.

Lorteije JA, Rusu SI, Kushmerick C, Borst JG (2009) Reliability and precision of the mouse calyx of Held synapse. J Neurosci 29:13770-13784.

Maycox PR, Deckwerth T, Hell JW, Jahn R (1988) Glutamate uptake by brain synaptic vesicles. Energy dependence of transport and functional reconstitution in proteoliposomes. J Biol Chem 263:15423-15428.

Mayer ML, Armstrong N (2004) Structure and function of glutamate receptor ion channels. Annu Rev Physiol 66:161-181.

McCormick DA, Connors BW, Lighthall JW, Prince DA (1985) Comparative electrophysiology of pyramidal and sparsely spiny stellate neurons of the neocortex. J Neurophysiol 54:782-806.

Mc Laughlin M, van der Heijden M, Joris PX (2008) How secure is in vivo synaptic transmission at the calyx of Held? J Neurosci 28:10206-10219.

Meyer J, Untiet V, Fahlke C, Gensch T, Rose CR (2019) Quantitative determination of cellular $\left[\mathrm{Na}^{+}\right]$by fluorescence lifetime imaging with CoroNaGreen. J Gen Physiol 151:1319-1331.

Preobraschenski J, Zander JF, Suzuki T, Ahnert-Hilger G, Jahn R (2014) Vesicular glutamate transporters use flexible anion and cation binding sites for efficient accumulation of neurotransmitter. Neuron 84:12871301.

Rizzoli SO, Betz WJ (2005) Synaptic vesicle pools. Nat Rev Neurosci 6:57-69.

Rose CR (2012) Two-photon sodium imaging in dendritic spines. Cold Spring Harb Protoc 2012:1161-1165.

Rudy B, McBain CJ (2001) Kv3 channels: voltage-gated K+ channels designed for high-frequency repetitive firing. Trends Neurosci 24:517526.

Sargent PB, Saviane C, Nielsen TA, DiGregorio DA, Silver RA (2005) Rapid vesicular release, quantal variability, and spillover contribute to the precision and reliability of transmission at a glomerular synapse. J Neurosci 25:8173-8187.

Sierksma MC, Borst JGG (2017) Resistance to action potential depression of a rat axon terminal in vivo. Proc Natl Acad Sci USA 114:4249-4254.

Sudhof TC (2004) The synaptic vesicle cycle. Annu Rev Neurosci 27:509547.

Sun JY, Wu LG (2001) Fast kinetics of exocytosis revealed by simultaneous measurements of presynaptic capacitance and postsynaptic currents at a central synapse. Neuron 30:171-182.

Tabb JS, Kish PE, Van Dyke R, Ueda T (1992) Glutamate transport into synaptic vesicles. J Biol Chem 267:15412-15418.

Taschenberger H, von Gersdorff H (2000) Fine-tuning an auditory synapse for speed and fidelity: developmental changes in presynaptic waveform, EPSC kinetics, and synaptic plasticity. J Neurosci 20:9162-9173.

Taschenberger H, Leão RM, Rowland KC, Spirou GA, von Gersdorff H (2002) Optimizing synaptic architecture and efficiency for high-frequency transmission. Neuron 36:1127-1143.

Wang LY, Kaczmarek LK (1998) High-frequency firing helps replenish the readily releasable pool of synaptic vesicles. Nature 394:384-388.

Wu LG, Borst JG (1999) The reduced release probability of releasable vesicles during recovery from short-term synaptic depression. Neuron 23:821832 .

Wu XS, Xue L, Mohan R, Paradiso K, Gillis KD, Wu LG (2007) The origin of quantal size variation: vesicular glutamate concentration plays a significant role. J Neurosci 27:3046-3056.

$\mathrm{Xu}$ J, Berret E, Kim JH (2017) Activity-dependent formation and location of voltage-gated sodium channel clusters at a CNS nerve terminal during postnatal development. J Neurophysiol 117:582-593.

Xue L, Sheng J, Wu XS, Wu W, Luo F, Shin W, Chiang HC, Wu LG (2013) Most vesicles in a central nerve terminal participate in recycling. J Neurosci 33:8820-8826.

Zhang Y, Huang H (2017) SK channels regulate resting properties and signaling reliability of a developing fast-spiking neuron. J Neurosci 37:1073810747 